\title{
A Stimuli-Responsive Macromolecular Gear: Interlocking Dynamic Helical Polymers with Foldamers
}

Rafael Rodríguez, Esteban Suárez-Picado, Emilio Quiñoá, Ricardo Riguera, Félix Freire

\section{Accepted Author Manuscript}

This is the peer reviewed version of the following article: R. Rodríguez, E. Suárez-Picado, E. Quiñoá, R. Riguera, F. Freire, Angew. Chem. Int. Ed. 2020, 59, 8616, which has been published in final form at https://doi.org/10.1002/anie.201915488. This article may be used for noncommercial purposes in accordance with Wiley Terms and Conditions for Use of Self-Archived Versions

\section{How to cite:}

R. Rodríguez, E. Suárez-Picado, E. Quiñoá, R. Riguera, F. Freire, Angew. Chem. Int. Ed. 2020, 59, 8616

\section{Copyright information:}

(C) 2020 Wiley-VCH Verlag GmbH \& Co. KGaA, Weinheim. This article may be used for noncommercial purposes in accordance with Wiley Terms and Conditions for self-archiving 


\title{
Stimuli-responsive Macromolecular Gear: Interlocking Dynamic Helical Polymers with Foldamers
}

\author{
Rafael Rodríguez, Esteban Suárez-Picado, Emilio Quiñoá, Ricardo Riguera, Félix Freire*
}

\author{
Centro Singular de investigación en Química Biolóxica e Materiais Moleculares (CiQUS) and Departamento de Química Orgánica \\ Universidade de Santiago de Compostela \\ E-15782 Santiago de Compostela, Spain \\ felix.freire@usc.es \\ Supporting information for this article is given via a link at the end of the document
}

\begin{abstract}
A macromolecular gear composed by a helical polyphenylacetylene (PPA) framework with short oligopeptide helices as substituents on the phenyl rings is described where the two helices (framework and substituents) are coupled and respond to the action of external stimuli by inverting the PIM sense or modifying the elongation. This gear is obtained by polymerization of the acetylene group introduced at the $\mathrm{C}$ - terminus of a short oligopeptide formed by achiral Aib units $(n=1-3)$ derivatized at the $N$-terminus by a single enantiomer $(R$ or $S$ ) of $\alpha$-methoxy- $\alpha$-trifluoromethylphenylacetic acid, (MTPA, Mosher reagent). Thus, the chiral information of the MTPA is transmitted to the achiral Aib fragment and harvested by the polyene backbone, which adopt preferentially a $\mathrm{P}$ or $\mathrm{M}$ helical scaffold. Variations on solvent polarity produce in the case of (R)-MTPA-(Aib) 1PPA changes on the helical sense and elongation due to variation on the conformational composition of the MTPA and aib moieties. In the case of (R)-MTPA-(Aib) 2 -PPA and (R)-MTPA-(Aib) ${ }_{3}$-PPA, the presence of polar solvents produces changes on the achiral Aib fragment that affect to the elongation of the helical scaffold but maintaining a certain orientation that induces a screw sense excess in the polyene main chain. The process is fully reversible, being possible to control the elongation and helical sense of the helical polymer by acting on the macromolecular structure adopted by the (Aib)n-MTPA fragment.
\end{abstract}

\section{Introduction}

Helical structures are structural motifs frequently observed in nature that are closely related to the function of molecules. Classical examples are the $\alpha$-helix in peptides and proteins, the helices found in polysaccharides or the DNA double helix. ${ }^{[1]}$

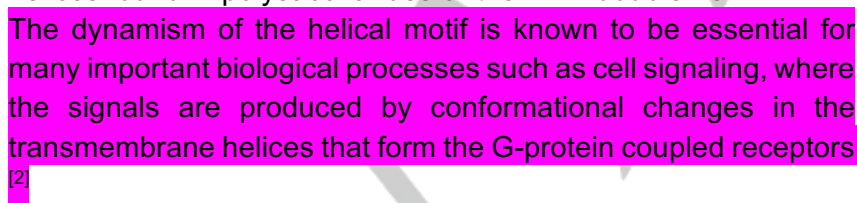

This structure/function relationship is the main reason for the development during the last decades of new molecular systems folded into helical structures such as foldamers or helical polymers, which can act as new biomimetic functional materials. [3]

In natural peptides or DNA, the presence of chiral monomers restricts the possibility of switching their helical sense due to the different stability of the two possible diastereomeric helices. ${ }^{3}$ This problem can be surpassed using polymers or foldamers constructed by non-chiral units, which show a low energy barrier between the two $(P / M)$ helical senses and therefore allowing the helical inversion by external stimuli. ${ }^{[3]}$ For instance, a preferred helical sense can be induced in polymers made by achiral monomers, by using a chiral additive, ${ }^{[4]}$ or by the classical Sergeants and Soldiers effect. ${ }^{[5]}$

In the case of dynamic helical polymers made by chiral monomers, the helical sense enhancement ${ }^{[6]}$ or inversion ${ }^{[7]}$ can be induced by external stimuli (i.e. temperature, solvents, metal ions, etc.), which act on the conformational composition of the monomerrepeating unit. An alternative way is to introduce a small amount of a chiral dopant into the polymer sequence - chiral coalition ${ }^{[8]}$ and chiral Sergeants and Soldiers effect ${ }^{[9]}$, where the stereochemistry of the copolymer components determines the helical sense of the polymer chain.

Peptidomimetics resort to oligomers formed by either non-natural amino acids or combinations of natural and non-natural amino acids that fold into helical structures -foldamers-mimicking natura peptides. ${ }^{[0]}$ Achiral residues can be used as building blocks, and the selective induction of the $P / M$ helical senses is achieved by linking (covalent or supramolecular interactions) a chiral amino acid at one of the two edges $-N$ or $C$ terminus. This phenomenon named as "domino effect" ${ }^{[11]}$ was described by Inai in oligomers formed by $\alpha$-aminoisobutyric acid (Aib) and $\alpha, \beta$ didehydrophenylalanine. ${ }^{[11]}$ Toniolo, ${ }^{[11]}$ Yashima ${ }^{[12]}$ and Clayden ${ }^{[13]}$ have done a great contribution in this field studying the folding of oligopeptides constituted mainly by achiral Ach, Aib or Aib/glycine residues. In these oligopeptides, the screw sense induction is produced by a chiral amino acid placed at the $\mathrm{N}$ or $\mathrm{C}$ termini of the sequence, whose stereochemistry determines the helical sense adopted by the foldamer ${ }^{[10]-[13]}$ Additionally, changes on the foldamer screw sense can be also obtained by manipulation of the hydrogen bonds of the helical scaffold, or by using $\mathrm{pH}$ or photochemistry as external stimuli. As a result, frequently, the changes of helical sense of the oligopeptide requires either changes on the absolute configuration of the peptide or on the net number of atoms in the foldamer. ${ }^{[10]-[13]}$ In previous works, achiral spacers consisting on a glycine or diglycine fragment were used to explore chiral teleinduction in PPAs. In those systems it was found that by increasing the number of glycine residues from 1 to 2 , the teleinduction decreases dramatically. ref

Herein we want to demonstrate that it is possible to induce a screw sense preference in PPA using achiral spacers that follow other chiral information transmission mechanism, such as chiral information harvesting. Ref 
Thus, we will show that introduction of the $(R)$ - or $(S)$ - $\alpha$-methoxy$\alpha$-trifluoromethylphenylacetic acid, (MTPA, Mosher reagent) at the $\mathrm{N}$-terminus of an achiral Aib oligopeptide, will generate a twisted structure with a preferred orientation. ${ }^{14]}$

In addition, the introduction of a 4-ethynylaniline group at the C-2 terminus of these peptides, followed by polymerization of the alkyne group will produce the corresponding poly(phenylacetylene)s (PPAs) ${ }^{[15]}$ behaving as macromolecular gears. In these systems, the chiral MTPA residue is expected to induce a major P/M orientation in the achiral oligopeptide, which through a chiral information harvesting mechanism will result in the adoption of a preferred $P / M$ screw sense in the polyene main chain.

Moreover, changes in solvent polarity could produce modifications in the ensemble of the MTPA-(Aib)n conformations, which should be further transmitted to the PPA as changes on the elongation and/or sense of the helix. ${ }^{[16]}$ referencia chiral harvesting

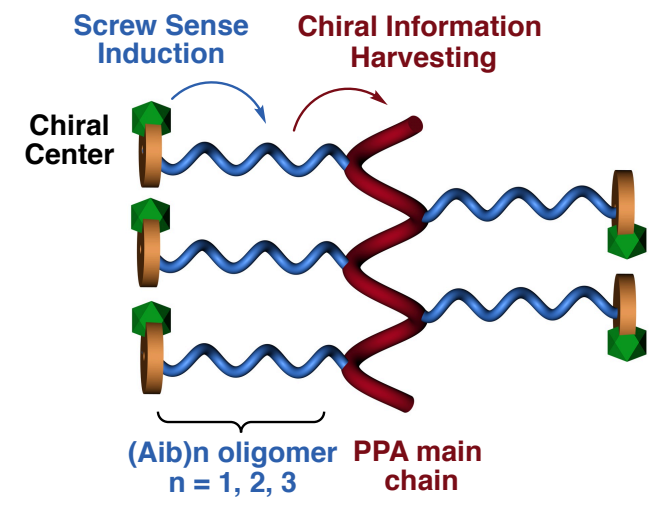

Scheme 1. Conceptual illustration of the chiral information harvesting mechanism in a PPA bearing a chiral $\mathrm{N}$ terminal Aib oligomer as pendant group.

\section{Results and Discussion}

To create a macromolecular gear, it is necessary first to design and test its different components. Our gear was planned to be formed by a helically tunable polyphenylacetylene skeleton, with oligopeptides as pendant groups possessing a switchable scaffold (Figure 1). Both types of helices, the main chain (polyene) and those at the substituents (oligopeptide), should be dynamic and connected in such a way that when an external stimulus act on the oligopeptide, changes in the ensemble of oligopeptide conformations would trigger structural changes on the polyene elongation and/or helical sense - through a chiral harvesting mechanism.

As chiral harvesting promoters, we selected oligopeptides made by achiral Aib residues that are known to adopt twisted structures such as $\beta$-turn or $3_{10}$ helices.ref Clayden In order to induce a biased screw sense, we introduced chiral $\alpha$-methoxy- $\alpha$ trifluoromethylphenylacetic acid (MTPA), at the $\mathrm{N}$-terminus. This chiral element was chosen because is known to respond to solvent polarity adopting different conformations and in fact, when MTPA was introduced as substituent on a PPA, those stimuli related conformational changes were strong enough to trigger changes in the polyenic helix. ${ }^{[16]}$

Thus, we prepared three different $\mathrm{H}-(\mathrm{Aib}) \mathrm{n}-\mathrm{COOH}$ oligomers $(\mathrm{n}=$ $1,2,3$ ) capped at the $\mathrm{N}$-terminus with the chiral $(R)$-MTPA unit and at the C-terminus with a 4-ethynilaniline [(R)-MTPA-(Aib $)_{n}$ PA] (See SI for synthetic details).

Experimental evidence was obtained showing that (R)-MTPA(Aib) $n-P A(n=1,2,3)$ oligomers adopt twisted macromolecular structures from $X$-ray diffraction.

Crystals of (R)-MTPA-(Aib)1-PA obtained from DCM/hexane solutions revealed the presence of an $M$ twisted structure stabilized by the presence of an antiperiplanar conformation between the carbonyl and methoxy group of the (R)-MTPA residue (Figure 2a).

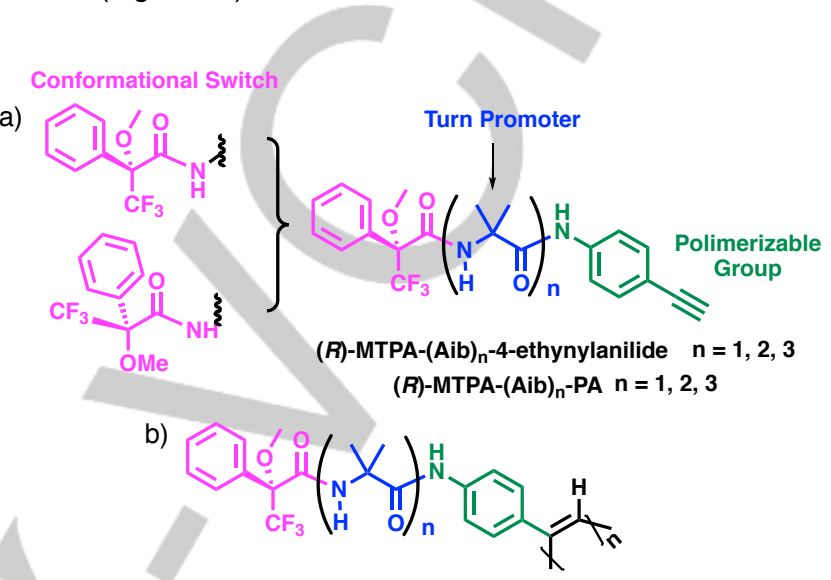

(R)-MTPA-(Aib) $)_{n}$-PPA $n=1,2,3$

Figure 1. (a) Foldamers (R)-MTPA-(Aib $)_{n}-\mathrm{PA} \quad(\mathrm{n}=1, \quad 2, \quad 3) . \quad$ (b) Poly(phenylacetylene)s (R)-MTPA-(Aib $)_{n}-\operatorname{PPA}(n=1,2,3)$

In the case of the oligomer containing two Aib residues - $(R)$ MTPA-(Aib)2-PA-, X-ray diffraction showed three different twisted structures that resemble a $\beta$-turn. The three structures are stabilized by a intramolecular hydrogen bond between a i and i+3 residues (Figure $2 b$ ). These three different helical scaffolds show an antiperiplanar orientation between the carbonyl and methoxy groups of the (R)-MTPA residue, but while two show $M$ orientations of the $(A i b)_{2}$ spacer, the third one shows a $P$ orientation (figure 2b). Pair fittings of those structures in the anilide region show that although the screw senses described by the spacer are different, the aromatic group of the MTPA is placed in similar spatial orientations related to the anilide group (Figure $2 \mathrm{x}$ and $\mathrm{SI})$.

Interestingly, in the case of (R)-MTPA-(Aib) ${ }_{3}$-PA, X-ray studies showed the coexistence in the same crystal unit of the two helical senses $-P$ and $M-$ that resemble 310 helices, stabilized by two consecutive i, i+3 hydrogen bonds (Figure 3c,d). In both helical structures, the $P$ and $M$ helical senses are defined by different conformations at the MTPA moiety: i) Antiperiplanar conformation between the carbonyl and methoxy groups (apome) associated to the right-handed twist $(P)$ in the oligomer (Figure 2xx); ii) Antiperiplanar conformation between the carbonyl and the trifluoromethyl group (apcF3) responsible for the adoption of a lefthanded screw sense $(M)$ (Figure $2 x x) .{ }^{[17]}$ 


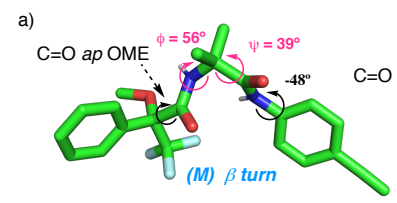

(R)-MTPA-Aib-PA

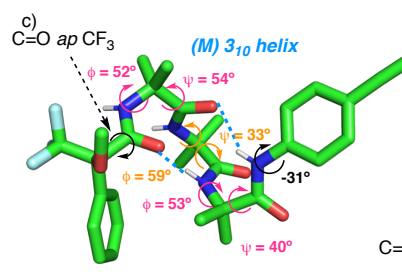

(R)-MTPA-(Aib) ${ }_{3}$-PA

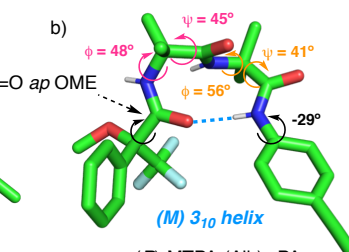

(R)-MTPA-(Aib) $)_{2}$-PA

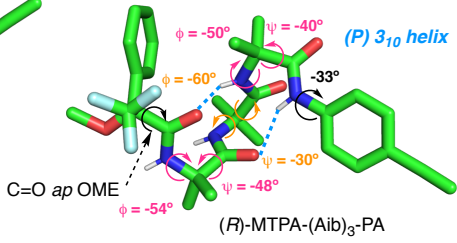

Figure 2. X-ray structures of (R)-MTPA-(Aib) $n-P A$ foldamers $(a) n=1,(b) n=2$, $(c, d) n=3$. revisar

These results are a clear evidence of a well-ordered structure in the achiral Aib fragment, which is needed to have an effective chiral induction in the final polyene.

In order to determine the presence of preferred twisted structures in solution, NMR, CD and Raman experiments were carried out in different solvents for the three (R)-MTPA-(Aib) $n$-PA $(n=1,2,3)$ oligomers.

2D-NMR (NOESY) showed in all cases the presence of sequential $\mathrm{NH}-\mathrm{NH}$ cross peaks confirming the presence of twisted structures Other long-distance NOEs gave further evidence of predominant peptide conformations (see SI for full details).

$\mathrm{CD}$ experiments also showed predominant conformations in $(R)$ MTPA-(Aib) ${ }_{1}$-PA and (R)-MTPA-(Aib) $)_{2}$-PA, which are affected by polarity changes, showing a fully or partial inversion of the $C D$ traces (Figure $3 \mathrm{xx}$ ). In the case of (R)-MTPA-(Aib) 3 -PA, although inversion was not observed from the $C D$ trace, conformational changes on the oligomer are also possible if the CD band of the aromatic MTPA interferes with the CD signal associated to the Aib fragment (calculos). This kind of phenomenon has been previously described in other Aib oligomers by Clayden's group.ref

Interestingly, the presence of a preferred helical structure was also supported by Raman studies that in the case of (R)-MTPA(Aib)3-PA showed a band at $1670 \mathrm{~cm}^{-1}$ considered as a $3_{10}$ helix marker (see Figure SXX).
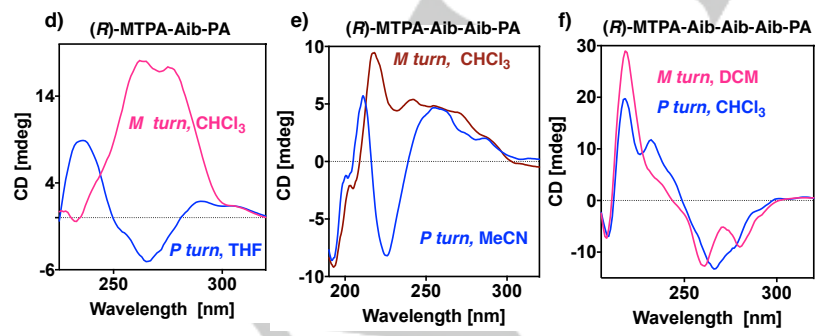

Figure 3. Representative NOEs and CD spectra of the different left- and righthanded secondary structures obtained for the $(R)$-MTPA-(Aib $)_{n}$-PA foldamers: $(a, d) n=1,(b, e) n=2,(c, f) n=3$.

The construction of the second element of the gear -the polyenic chain - was addressed by rhodium catalyzed polymerization of the terminal alkyne contained in the C-terminus of the foldamers. ${ }^{[19]}$

Thus, $(R)$-MTPA-(Aib) $n-P A(n=1,2,3)$ were polymerized into the corresponding poly(phenylacetylene)s (PPAs) by using a $\mathrm{Rh}(\mathrm{I})$ catalyst. Polymers, $(R)-\mathrm{MTPA}-(\mathrm{Aib}) \mathrm{n}$-PPA $(\mathrm{n}=1-3)$ were obtained in high yield, with high content of cis double bonds as inferred by ${ }^{1} \mathrm{H}$ NMR spectra (See S12) and Raman (See S16). The numberaverage molecular weight $(M n)$ and distribution $(M n / M w)$ of the oligomers was determined by size exclusion chromatography (SEC) -34525, 2.25; 35660, 2.02; 39980, 2.11 for (R)-MTPAAib-PPA, $\quad(R)$-MTPA-Aib 2 -PPA and $(R)$-MTPA-Aib 3 -PPA respectively - (See Page $S 18$ for additional information). CD studies of $(R)$-MTPA-(Aib) $n$-PPA $(n=1,2,3)$ show CD traces typical for PPA helical structures.

Therefore, this fact indicates the presence of an effective chiral information transmission mechanism from the chiral MTPA moiety to the polyene backbone. This mechanism varies from a chiral teleinduction to a chiral harvesting process depending on the length of the achiral spacer. Based on the structural information obtained from X-ray studies of the monomers (see above), teleinduction should be active mainly in (R)-MTPA-(Aib) ${ }_{1}$-PPA due to the close location of the chiral MTPA towards the polyene backbone, while chiral harvesting should occur mainly in $(R)$ MTPA-(Aib)3-PPA, where the chiral center is placed far away from the polyene. In case of (R)-MTPA-(Aib)2-PPA both mechanisms could be operative.

Moreover, CD studies show that (R)-MTPA-(Aib) 1-PPA undergoes a helix inversion accompanied with an elongation of the polyene by solvent polarity changes. However, (R)-MTPA(Aib)2-PPA and (R)-MTPA-(Aib) ${ }_{3}$-PPA just show variations on the stretching of their helical scaffolds with increasing polarity, maintaining in most cases the same helical sense preference.

STD 2D-NMR at different mixing times give us information about the spatial proximity between functional groups at the pendant. Sequential $\mathrm{NH}-\mathrm{NH}$ crosspeaks were found in the NMR spectra of (R)-MTPA-(Aib)n-PPA ( $\mathrm{n}=1,2,3)$, in addition to other long distance NOEs either in polar and low-polar solvents, which indicate the presence of well-organized arrangement for the $(R)$ MTPA-(Aib)n fragment. This is a necessary requirement to produce a helical sense bias in the polyene chain.

Finally, while the helix inversion of (R)-MTPA-(Aib)1-PPA by polarity changes is commanded by conformational changes at the MTPA moiety, the helical stretching in the polyene backbones of all the (R)-MTPA-(Aib) $n$-PPA $(n=1,2,3)$ could arise from other phenomena. In order to clarify this point, four different PPAs were designed and synthetized. Two of them contain a racemic mixture of MTPA - (rac)-MTPA-(Aib)n-PPA $(n=2,3)$, while the other two contain a free $\mathrm{N}$-terminus Aib oligomer $-\mathrm{H}-(\mathrm{Aib}) \mathrm{n}$-PPA $(n=2,3)$. In all cases, the CD spectra were null as expected and UV-vis studies revealed a bathochromic shift of the polyene backbone when the polarity increased (See SI).

This fact indicates that the interaction of the polar solvents with the Aib residues is the phenomenon responsible of the helical stretching observed in all Aib containing PPAs.

Interestingly, although these Aib oligomer-polar solvent interactions affect the elongation of the PPAs, active CD spectra are still observed in some cases. This fact indicates that increasing solvent polarity produces changes in the ensemble of Aib oligomer conformations, including the presence of some unfolding states, the overall orientation of the achiral spacer -Aib 
oligomer-is still biased into a preferred screw sense due to the presence of the (R)-MTPA moiety placed at the N-terminus.

All these structural changes are fully reversible, and are also operative in the solid state, where the yellow to red color change observed for (R)-MTPA-(Aib)n-PPA also works when the solid is placed under different solvent atmospheres —orange $\left(\mathrm{CHCl}_{3}\right)$, red $(\mathrm{MeOH})$ -
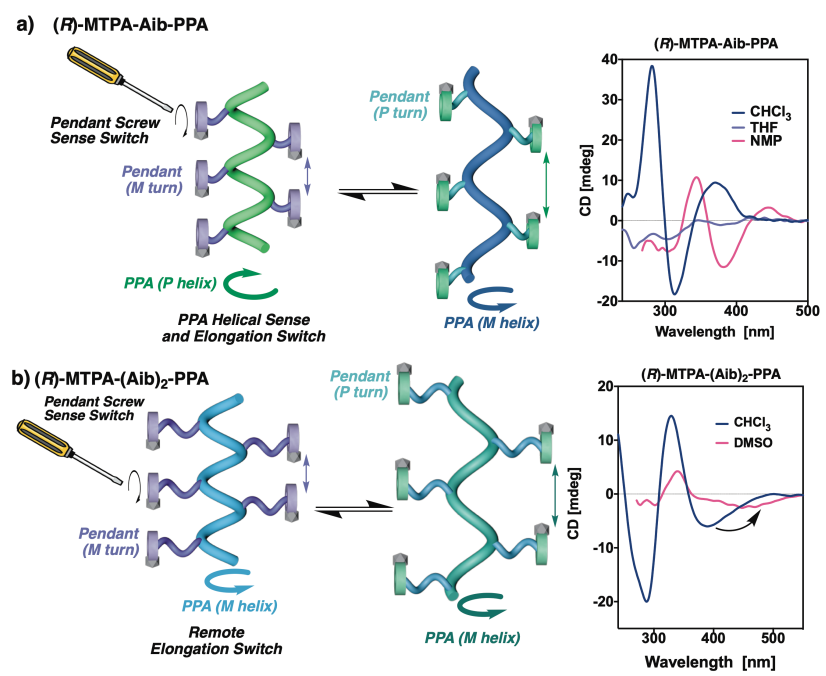

Figure 4. (a) Conceptual illustration of the helix inversion and stretching process of $(R)$-MTPA-Aib-PPA; (b) and conceptual illustration of the stretching process of $R$ )-MTPA-(Aib)2-PPA.

\section{Conclusion}

We have demonstrated that the presence at the $\mathrm{N}$-terminus of short non chiral Aib oligomers $(n=1,2,3)$, of a single enantiomer of MTPA allows the selective folding of the chain into $P$ or $M$ helical senses, by shifting the polarity of the solvent. This action is due to the conformational change produced in the chiral MTPA unit of $(R)$-MTPA-(Aib) $n$-PA $(n=1,2,3)$ that is transmitted to the oligopeptide chain via screw sense induction.

Introduction of a 4-ethynylaniline group at the C-terminus of those oligopeptides followed by polymerization of the alkyne, produced the corresponding poly(phenylacetylene)s PPA - $(R)$-MTPA(Aib) $n$-PPA $(n=1,2,3)$ - that were shown to act as a molecular gear where the helical sense/elongation of the polyenic skeleton is controlled by the helical sense of the oligopeptide chain that in turn, obeys to the conformational composition of the terminal $R$ MTPA unit, shifted by the polarity of the media.

In this way, solvent polarity changes makes the oligopeptide substituents of PPA - $(R)$-MTPA-(Aib) $n$-PA $(n=1,2,3)$ - to vary their $P / M$ screw sense preference, which triggers a structural change on the polyenic skeleton -helical sense and/or elongation- through an amplification effect.

Interestingly, the transmission to the polyene helix of the changes in the oligopeptide substituents, depends on the length of the oligopeptide. Thus, in the case of a polymer substituted by the shortest oligomer PPAs -(R)-MTPA-(Aib)n-PA $(n=1)$-, a change in polarity inverts the helical sense of the oligopeptide substituents and that of the polyene skeleton that shows also an elongation of the chain probably to release the strain gained with the conformational change at the pendant (Figure 6a).
In contrast, the polyene chain of the polymers containing two or three Aib residues as substituents, PPAs - $(R)$-MTPA-(Aib) ${ }_{n}-P A$ $(n=2,3)-$, respond to the oligopeptide inversion just with elongation and without helical inversion. This is so probably because the energy penalty to accommodate the larger substituents $(n=2,3)$ by inversion of the helix is much higher than by increasing the dihedral angle between conjugated double bonds (Figure 6a,b).

\section{As stated above, other achiral oligomers such as (R)-MTPA- (Gly) ${ }_{2}$-PPA}

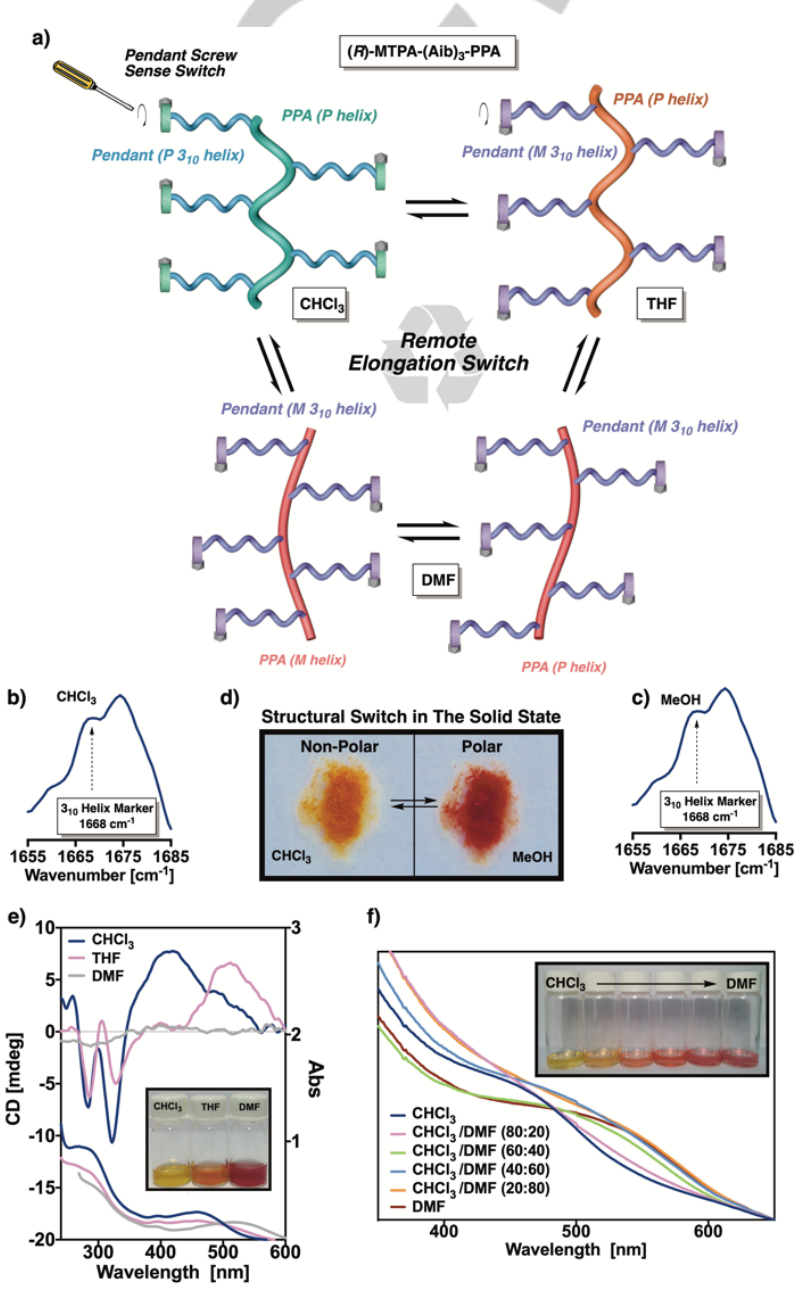

Figure 5. (a) Schematic illustration of the stretching process along the three different secondary structures of (R)-MTPA-(Aib) ${ }_{3}$-PPA. (b) and (c) Raman spectra of (R)-MTPA-(Aib) $)_{3}$-PPA in $\mathrm{CHCl}_{3}$ and $\mathrm{MeOH}$ showing characteristic Aib $3_{10}$ Helix marker bands. (d) Pictures of $(R)$-MTPA-(Aib) 3 -PPA depicting the structural switch from compressed to stretched structure in the solid state. (e) $\mathrm{CD} / \mathrm{UV}$-Vis spectra of $(R)$-MTPA-(Aib) ${ }_{3}$-PPA in different solvents showing the three different helical states with different elongation degree. (f) UV-Vis experiment and inset picture of the colorimetric change throughout the titration from compressed to stretched structure $\left(\mathrm{CHCl}_{3}\right.$ to DMF) of $(R)-\mathrm{MTPA}-(\mathrm{Aib})_{3}-$ PPA.

\section{Acknowledgements}

Financial support from MINECO (CTQ2015-70519-P), Xunta de Galicia (ED431C 2018/30, Centro singular de investigación de Galicia accreditation 2016-2019, ED431G/09 and postdoctoral fellowship for R. R.) and the European Regional Development 
Fund (ERDF) is gratefully acknowledged. E. S. P. thanks MINECO for his FPU fellowship.

Keywords: Foldamer • Helical Polymer • Screw sense control • Aib - chirality

[1] a) E. Yashima, N. Ousaka, D. Taura, K. Shimomura, T. Ikai, K. Maeda, Chem. Rev., 2016, 116, 13752-13990; b) Z. Yu, S. Hecht, Chem. Commun., 2016, 52, 6639-6653; c) E. Schwartz, Koepf, M. H. J. Kitto, R. J. M. Nolte, A. E. Rowan, Polym. Chem., 2011, 2, 33-47; d) lida, H.; Yashima, E. Synthesis and Application of Helical Polymers with Macromolecular Helicity Memory, in Polymeric Chiral Catalyst Design and Chiral Polymer Synthesis, ed. S. Itsuno, John Wiley \& Sons, Hoboken, NJ, USA, 2011, ch. 7, p. 201-222; e) B. M. Rosen, C. J. Wilson, D. A. Wilson, M. Peterca, M. R. Imam, V. Percec, Chem. Rev., 2009, 109 6275-6540; f) E. Yashima, K. Maeda, H. lida, Y. Furusho, K. Nagai, Chem. Rev., 2009, 109, 6102-6211; g) J. G. Rudick, V. Percec, Acc. Chem. Res., 2008, 41, 1641-1652; h) D. Pijper, B. L. Feringa, Soft Mater, 2008, 4, 1349-1372; i) E. Yashima and K. Maeda, in Foldamers: Structure, Properties, and Applications, ed. S. Hecht and I. Huc, WileyVCH, Weinheim, 2007, pp. 331-366; j) E. Yashima, K. Maeda, Y. Furusho, Acc. Chem. Res., 2008, 41, 1166-1180; k) J. J. L. M. Cornelissen, A. E. Rowan, R. J. M. Nolte, N. A. J. M. Sommerdijk, Chem. Rev., 2001, 101, 4039-4070; I) T. Nakano, Y. Okamoto, Chem. Rev. 2001, 101, 4013-4038.

[2] S. L. Cockroft, Nat. Chem., 2017, 9, 406-407.

[3] a) Y. Nagata, R. Takeda, M. Suginome, ACS Cent. Sci., 2019, 5, 12351240; b) T. Yamamoto, R. Murakami, S. Komatsu, M. Suginome, J. Am. Chem. Soc., 2018, 140, 3867-3870; c) K. Maeda, E. Yashima, Top. Curr. Chem., 2017, 375:72; d) F. Freire, J. M. Seco, E. Quiñoá, R. Riguera, Angew. Chem., Int. Ed.; 2011, 50, 11692-11696; e) T. Yamamoto, T. Yamada, Y. Nagata, M. Suginome, J. Am. Chem. Soc. 2010, 132, 78997901; f) E. Yashima, K. Maeda, Y. Okamonoto, Nature, 1999, 399, 449451.

[4] a) S. Arias, J. Bergueiro, F. Freire, E. Quiñoá, R. Riguera, Small, 2016, 12, 238-244; b) J. Bergueiro, F. Freire, E. P. Wendler, J. M. Seco, E. Quiñoá, R. Riguera, Chem. Sci., 2014, 5, 2170-2176; c) V. Jain, K.-S. Cheon, K. Tang, S. Jha, M. M. Green, Isr. J. Chem., 2011, 51, 10671074; d) M. M. Green, J.-W. Park, T. Sato, A. Teramoto, S. Lifson, R. L. B. Selinger, J. V. Selinger, Angew. Chem. Int. Ed., 1999, 38, 3138-3154; e) S. K. Jha, K.-S. Cheon, M. M. Green, J. V. Selinger, J. Am. Chem. Soc., 1999, 121, 1665-1673; f) M.M. Green, N.C. Peterson, T. Sato, A. Teramoto, R. Cook, S. Lifson, Science, 1995, 268, 1860-1866.

[5] R. Ishidate, A. J. Markvoort, K. Maeda, E. Yashima, J. Am. Chem. Soc., 2019, 141, 7605-7614.

[6] a) S. Arias, M. Núñez-Martínez, E. Quiñoá, R. Riguera, F. Freire, Polym. Chem., 2017, 8, 3740-3745; b) T. Van Leeuwen, G. H. Heideman, D. Zhao, S. J. Wezenberg, B. L. Feringa, Chem. Commun., 2017, 53, 63936396. c) M. Alzubi, S. Arias, I. Louzao, E. Quiñoá, R. Riguera, F. Freire, Chem. Commun., 2017, 53, 8573-8576; d) I. Louzao, J. M. Seco, E. Quiñoá, R. Riguera, Angew. Chem., Int. Ed., 2010, 49, 1430-1433; e) H. Goto, H. Q. Zhang, E. Yashima, Macromolecules, 2003, 36, 1480-1486.

[7] S. Arias, R. Rodríguez, E. Quiñoá, R. Riguera, F. Freire, J. Am. Chem. Soc., 2018, 140, 667-674.

[8] K. Cobos, E. Quiñoá, R. Riguera, F. Freire, J. Am. Chem. Soc.; 2018, 140, 12239-12246

[9] a) D. J. Hill, M. J. Mio, R. B. Prince, T. S. Hughes, J. S. Moore, Chem. Rev., 2001, 101, 3893-4012; b) S. H. Gellman, Acc. Chem. Res., 1998, 31, 173-180.

[10] a) J. P. Mazaleyrat, K. Wright, A. Gaucher, N. Toulemonde, M. Wakselman, S. Oancea, C. Peggion, F. Formaggio, V. Setnička, T. A. Keiderling, C. Toniolo, J. Am. Chem. Soc., 2004, 126, 12874-12879; b) C. Toniolo, M. Crisma, F. Formaggio, C. Peggion. Biopolymers 2001, 60, 396-419 (c) C. Toniolo, E. Benedetti, Trends Biochem. Sci., 1991, 16, 350-353.

[11] a) N. Ousaka, Y. Inai, R. Kuroda, J. Am. Chem. Soc., 2008, 130, 1226612267; b) N. Ousaka, Y. Inai, J. Am. Chem. Soc., 2006, 128, 1473614737; c) Y. Inai, N. Ousaka, T. Okabe, J. Am. Chem. Soc., 2003, 125,
8151-8162. d) Y. Inai, Y. Ishida, K. Tagawa, A. Takasu, T. Hirabayashi, J. Am. Chem. Soc., 2002, 124, 2466-2473; e) Y. Inai, K. Tagawa, A. Takasu, T. Hirabayashi, T. Oshikawa, M. Yamashita, J. Am. Chem. Soc., 2000, 122, 11731-11732.

[12] a) A. Urushima, N. Ousaka, E. Yashima, Chem. Asian J.; 2018, 13, 31503154; b) N. Ousaka, F. Mamiya, Y. Iwate, K. Nishumura, E. Yashima, Angew. Chem. Int. Ed., 2017, 56, 791-795; c) F. Mamiya, N. Ousaka, E. Yashima, Angew. Chem. Int. Ed., 2015, 54, 14442-14446; d) N. Ousaka, Y. Takeyama, E. Yashima, Nat. Chem., 2011, 3, 856-861.

[13] a) G. A. Francis, N. Eccles, S. J. Pike, R. A. Brown, G. F. S. Whitehead, J. Raferty, S. J. Webb, J. Clayden, Chem. Sci., 2018, 9, 6860-6870, b) F. G. A. Lister,B. A. F. Le Bailly, S. J. Webb, J. Clayden, Nat. Chem., 2017, 9, 420-425; c) D. Mazzier, M. Crisma, M. De Poli, G. Marafon, C. Peggion, J. Clayden, A. Moretto, J. Am. Chem. Soc., 2016, 138, 80078018; d) M. De Poli, W. Zawodny, O. Quinonero, M. Lorch, S. J. Webb, J. Clayden, Science, 2016, 352, 575-580; e) J. E. Jones, V. Diemer, C. Adam, J. Raferty, R. E. Ruscoe, J. Sengel, M. I. Wallace, A. Bader, S. L. Cockroft, J. Clayden, S. J. Webb, J. Am. Chem. Soc., 2016, 138, 688695; f) B. A. F. Le Bailly,J. Clayden, Chem. Commun., 2016, 52, 48524863; g) B. A. F. Le Bailly, L. Byrne, J. Clayden, Angew. Chem. Int. Ed., 2016, 55, 2132-2136; h) J. Brioche, S. J. Pike, S. Tshepelevitsh, I. Leito, G. A. Morris, S. J. Webb, J. Clayden, J. Am. Chem. Soc., 2015, 137, 6680-6691; i) S. J. Pike, T. Boddaert, J. Raferty, S. J. Webb, J. Clayden, New J. Chem., 2015, 39, 3288-3294. j) L. Byrne, J. Solá, T. Boddaert, T.;Marcelli, R. W. Adams, G. A. Morris, J. Clayden, Angew. Chem. Int. Ed., 2014, 53, 151-155; k) R. A. Brown, V. Diemer, S. J. Webb, J. Clayden, Nat. Chem., 2013, 5, 853-860; I) T. Boddaert, J. Solá, M. Helliwell, J. Clayden, Chem. Commun., 2012, 48, 3397-3399; m) J. Solá, G. A. Morris, J. Clayden, J. Am. Chem. Soc., 2011, 133, 3712-3715; n) J. Solá, M. Helliwell, J. Clayden, Biopolymers, 2011, 95, 755-762; o) J. Solá, S. P. Fletcher, A. Castellanos, J. Clayden, Angew. Chem. Int. Ed., 2010, 49, 6836-6839; p) J. Solá, M. Helliwell, J. Clayden, J. Am. Chem. Soc., 2010, 132, 4548-4549; q) J. Clayden, A. Castellanos, J. Solá, G. A. Morris, Angew. Chem. Int. Ed., 2009, 48, 5962-5965.

[14] a) J. A. Dale, H. S. Mosher, J. Am. Chem. Soc., 1973, 95, 512-519. (b) J. A. Dale, D. L. Dull, H. S. Mosher, J. Org. Chem., 1969, 34, 2543-2549.

[15] a) R. Rodríguez, E. Quiñoá, R. Riguera, F. Freire, Small, 2019, 15, , 1805413. b) K. Maeda, H. Hirose, N. Okoshi, K. Shimomura, Y. Wada, T. Ikai, S. Kanoh, E. Yashima, J. Am. Chem. Soc., 2018, 140, 3270-3276. c) E. Suárez-Picado, E. Quiñoá, R. Riguera, F. Freire, Chem. Mater., 2018, 30, 6908-6914; d) R. Rodríguez, S. Arias, E. Quiñoá, R. Riguera, F. Freire, Nanoscale, 2017, 9, 17752-17757; e) F. Ishiwari, K. Nakazono, Y. Koyama, T. Takata, Angew. Chem. Int. Ed., 2017, 56, 14858-14862; f) R. Rodríguez, E. Quiñoá, R. Riguera, F. Freire, J. Am. Chem. Soc., 2016, 138, 9620-9628; g) F. Freire, E. Quiñoá, R. Riguera, Chem. Commun., 2017, 53, 481-492; h) R. Rodríguez, J. Ignés-Mullol, F. Sagués, E. Quiñoá, R. Riguera, F. Freire, Nanoscale, 2016, 8, 33623367; i) N. Zhu, K. Nakazono, T. Takata, Chem. Commun., 2016, 52, 3647-3649; j) L. Liu, T. Namikoshi, Y. Zang, T. Aoki, S. Hadano, Y. Abe, I. Wasuzu, T. Tsutsuba, M. Teraguchi, T. Kaneko, J. Am. Chem. Soc., 2013, 135, 602-605; k) V. Percec, J. G. Rudick, M. Peterca, P. A. Heiney, J. Am. Chem. Soc., 2008, 130, 7503-7508; I) K. K. L. Cheuk, B. S. Li, J. W. Y. Lam, B. Z. Tang, Macromolecules, 2008, 41, 5997-6005; (m) V. Percec, E. Aqad, M. Peterca, J. G. Rudick, L. Lemon, J. C. Ronda, B. B. De, P. A. Heiney, E. W. Meijer, J. Am. Chem. Soc., 2006, 128, 1636516372; n) K. Maeda, H. Mochizuki, M. Watanabe, E. Yashima, J. Am. Chem. Soc., 2006, 128, 7639-7650; o) J. W. Y. Lam, B. Z. Tang, Acc. Chem. Res., 2005, 38, 745-754; p) F. Sanda, K. Terada, T. Masuda, Macromolecules, 2005, 38, 8149-8154; q) B. S. Li, K. K. L. Cheuk, L. Ling, J. Chen, X. Xiao, C. Bai B. Z. Tang, Macromolecules, 2003, 36, 7785 ; r) K. K. L. Cheuk, J. W. Y. Lam, J. Chen, M. L. Laiand, B. Z. Tang, Macromolecules, 2003, 36, 5947-5959.

[16] a) R. Rodríguez, E. Quiñoá, R. Riguera, F. Freire, Chem. Mater., 2018, 30, 2493-2497; b) S. Leiras, F. Freire, J. M. Seco, E. Quiñoá, R. Riguera, Chem. Sci., 2015, 6, 246-253; c) S. Leiras, F. Freire, J. M. Seco, E. Quiñoá, R. Riguera, Chem. Sci., 2013, 4, 2735-2743.

[17] a) B. Fernández, R. Rodriguez, E. Quiñoá, R. Riguera, F. Freire. ACS Omega, 2019, 4, 5233-5240; b) B. Fernández, R. Rodríguez, A. Rizzo, 
E. Quiñoá, R. Riguera, F. Freire, Angew. Chem. Int. Ed., 2018, 57, 36663670 .

[18] M. G. Lizio, V. Andrushchenko, S. J. Pike, A. D. Peters, G. F. S. Whitehead, I. J. Vitórica-Yrezábal, S. T. Mutter, J. Clayden, P. Bour, E. W. Blanch, S. J. Webb, Chem. Eur. J.; 2018, 24, 9399-9408.

[19] a) Z. Ke, S. Abe, T. Ueno, K. Moruma, J. Am. Chem. Soc., 2011, 133 7926-7941; b) M. G. Mayershofer, O. Nuyken, J. Polym. Sci., Part A: Polym. Chem., 2005, 43, 5723-5747; c) M. Tabata, W. Yang, K. Yokota, Polym. J., 1990, 22, 1105-1107; d) A. Furlani, C. Napoletano, M. V. Russo, W. Feast, Polym. Bull., 1986, 16, 311-317; e) C. I. Simionescu, V. Percec, Polym. Sci., Polym. Chem. Ed., 1980, 18, 147-155; f) C. I. Simionescu, V. Percec, S. Dumitrescu, J. Polym. Sci., Polym. Chem. Ed., 1977, 15, 2497-2509. 


\section{Entry for the Table of Contents}

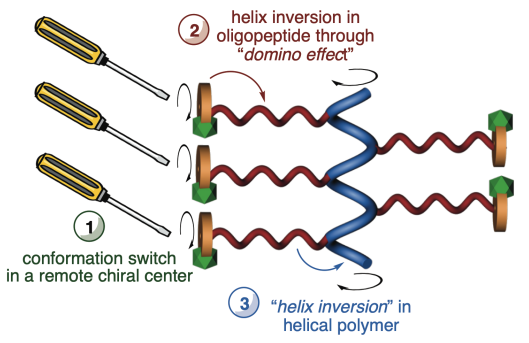

Macromolecular gear. Long-range chiral induction is produced in a polyphenylacetylene (PPA) that bears an achiral Aib oligomer capped at the N-termini with a chiral acid (Mosher reagent). The chiral residue induces a screw sense preference into the Aib oligomer which is further transmitted to the PPA by adoption of an excess of a single-handed helix. Conformational changes at the chiral residues produces changes in the helical sense of the oligopeptide foldamer which are further transmitted to the polymer main chain through changes in the elongation and/or helical sense.

Institute and/or researcher Twitter usernames: @ciqususc, @felixfreirelab, 